\title{
¿Guerra de naciones? Movilización política, conflictividades y violencias entre naciones universitarias en la Salamanca del periodo Barroco
}

\author{
A War of Nations? Political Mobilization, Unrest \\ and Violence among University Nations in Salamanca \\ during the Baroque Period
}

\author{
Gustavo Hernández Sánchez* \\ Universidad de Salamanca
}

DOI: http://dx.doi.org/10.20318/cian.2016.3439

$\begin{array}{ll}\text { Recibido: } & 27 / 04 / 2016 \\ \text { Aceptado: } & 24 / 10 / 2016\end{array}$

Resumen: El fenómeno de la violencia en la temprana Edad Moderna castellana como algo estructural está siendo revisado en la actualidad por algunas líneas de investigación que comienzan a interpretar esta cuestión desde el punto de vista de la movilización política. Dentro de esta nueva perspectiva, la atmósfera universitaria y las conflictividades de este sector específico de la población dentro de las ciudades que poseen universidad aparecen como un terreno abonado para la ampliación de los estudios sobre el tema, así como sobre la propia historia universitaria. Emergen de este modo las violencias y conflictividades entre grupos de estudiantes, agrupados en naciones universitarias que
Abstract: The phenomenon of violence during the early modern period of Castille as something structural is a topic currently revisited by certain lines of research that are starting to interpret the issue from the perspective of political mobilization. From this new perspective, the university atmosphere and the unrest in this specific subset of the population within university towns and cities take shape as a breeding ground for the expansion of studies carried out on the matter, as well as on the history of universities itself. As a result, violence and disturbance emerge among groups of students, clustered in university nations that comprise genuine power groups within the institution, as a struggle

*gustavohistoria@usal.es 
constituyen auténticos grupos de poder dentro del Estudio, como una lucha por el poder y gobierno universitario con fines políticos a menudo bien orientados y organizados para tratar de hacerse con el control de la Universidad. En el presente artículo analizaremos algunos casos referentes a la de Salamanca durante el periodo barroco en los que se dan cita estos elementos.

Palabras clave: nación universitaria, movilización política, violencia, Universidad de Salamanca, Barroco. for power and university government with political goals, often well directed and organized in an attempt to wrestle control over the University. This article will examine a range of cases from Baroque period of University of Salamanca in which these elements are brought together.

Keywords: university nation, political mobilization, violence, University of Salamanca, Baroque period.

\section{Introducción: nación, cofradía y cuadrilla...una aclaración terminológica ${ }^{1}$}

Una de las líneas de investigación más interesantes que ofrece la historia de las universidades en la temprana Edad Moderna castellana desde sus fundaciones medievales es la del estudio de las "naciones universitarias". A pesar de ello, pocos son los investigadores, salvo para el caso de la Universidad de Salamanca, que se han adentrado en esta importante veta que ofrecen los archivos universitarios ${ }^{2}$.

En primer lugar, debemos señalar qué entendemos por el concepto de "nación universitaria". Por lo que respecta al periodo Barroco, es decir, finales del siglo XVI y primera mitad del XVII aproximadamente (que se corresponde con la cronología de nuestro trabajo), el término "nación" hace referencia, de acuerdo con el Tesoro de la lengua castellana (1611) de Sebastián de Covarrubias, al "reino o provincia extendida, como la nación española"3. Una definición

\footnotetext{
${ }^{1}$ El presente artículo fue presentado como comunicación en el VI Congreso Internacional e Interdisciplinar de Jóvenes Historiadores: "Las violencias y la Historia", celebrado en la Universidad de Salamanca. Facultad de Geografía e Historia, 11-13 marzo 2015, y organizado por la Asociación de Jóvenes Historiadores (AJHIS).

${ }^{2}$ Del estudio clásico de Pearl Kibre, The Nations in the Medieval Universities (Cambridge: Mediaeval Academy of America, 1948). citado en Historia de la Universidad en Europa, vol. II. Las Universidades en la Europa Moderna Temprana (1500-1800), ed. Hilde de Ridder-Symoes (Bilbao: Universidad del País Vasco, 1999), 163-170. que recoge una breve recopilación de obras sobre naciones universitarias en países europeos, a estudios más concretos: Pascual Tamburri. "La nación de las Indias en la Universidad de Bolonia (siglos XIV-XIX). Raíces medievales de la cultura hispano-americana," Espacio, Tiempo y Forma, serie IV, Historia Moderna, t. 13 (2000): 339-364; pocos son los autores que se han acercado a este campo de estudio.

${ }^{3}$ Sebastián de Covarrubias. Tesoro de la lengua castellana o española, Ed. integral e ilustrada de Ignacio Arellano y Rafael Zafra, (Madrid: Iberoamericana, 2006), 1305.
} 
un tanto imprecisa. La definición posterior, en el Diccionario de autoridades (T. IV, 1734), tal vez sea algo más precisa: "El acto de nacer. En este sentido se usa en el modo de hablar De nación, en lugar de Nacimiento (...)"4. Será en este sentido, lugar de nacimiento, como la entenderemos nosotros, con el fin de escapar a cualquier debate que este término pudiera suscitar en la actualidad ${ }^{5}$.

Por lo que respecta a la historiografía de las universidades, y concretamente a la universidad de Salamanca, es sin duda Luis E. Rodríguez-San Pedro el autor que más ampliamente ha tratado el estudio de las naciones universitarias ${ }^{6}$. Él da las definiciones más pertinentes sobre el concepto de

\footnotetext{
${ }^{4}$ Diccionario de autoridades (T. IV, 1734), disponible en http://web.frl.es/DA.html [consultado el 17 de junio de 2015].

${ }^{5}$ No debe confundirse el término de "nación" con sus significaciones actuales, debate que no deja indiferentes a los historiadores modernistas: José Ignacio Ruíz Rodríguez, "Protonacionalismo e identidades en Europa," en Construyendo identidades: del protonacionalismo a la nación, ed. José Ignacio Ruíz Rodríguez e Igor Sosa Mayor (Alcalá: Universidad de Alcalá, 2013), 13-29. De los mismos autores: Identidades confesionales y construcciones nacionales en Europa (ss. XVI-XIX) (Alcalá: Universidad de Alcalá, 2012). Nuestra postura, en todo caso, respecto al periodo actual, sería más cercana a la propuesta lanzada en su día por Eric Hobsbawm, quien entendió el nacionalismo como un fenómeno estrictamente contemporáneo, de los siglos XIX y XX, entendiéndose el término de forma restrictiva. Hobsbawm relacionó los procesos de construcción de identidades colectivas o nacionales que buscaron sus raíces en la Temprana Edad Moderna, la Edad Media o incluso antes, con procesos de construcción característicos de la forma de Estado surgida en dichos siglos, tras la revolución francesa, y apoyados por una historiografía muy comprometida con la tarea de construir dichas identidades. Eric Hobsbawm. Naciones y nacionalismo desde 1780 (Barcelona: Crítica, 1991). En esta línea de descargar el significado actual del concepto de "corporaciones de nación" y estudiar los vínculos entre las élites locales y provinciales con la Corte, así como otros espacios de poder tales como el universitario, como clave de la articulación de una Monarquía agregativa a nivel global y en la conformación del Estado moderno: Oscar Recio Morales. "Los espacios físicos de representatividad de las comunidades extranjeras en España. Un estado de la cuestión," en Las corporaciones de nación en la Monarquía Hispánica (1580-1750). Identidad, patronazgo y redes de sociabilidad, ed. Baernardo J. García García y Oscar Recio Morales (Madrid: Fundación Carlos de Amberes, 2014) 13-32. Del mismo autor: "Redes de nación y espacios de poder en la Monarquía Hispánica: un estado de la cuestión," en Redes de nación y espacios de poder. La comunidad irlandesa en España y la América española, 1600-1825, ed. Oscar Recio Morales (Valencia: Ministerio de Defensa, 2012) 37-52. Con carácter más general: Antonio ÁlvarezOssorio Alvariño y Bernardo J. García García (ed). La Monarquía de las naciones. Patria, nación y naturaleza en la Monarquía de España (Madrid: Fundación Carlos de Amberes, 2004).

${ }^{6}$ Otros estudios: Ángel Marcos de Dios. "Estudiantes de Brasil en la Universidad de Salamanca durante los siglos XVI y XVII," Revista de Historia, 5, (1976): 215-230. Del mismo autor: Portugueses na Universidade de Salamanca (1550-1580) (Salamanca: Luso-Española de Ediciones, 2005). 0 el más reciente de Francisco Javier Rubio Muñoz, "La nación de Extremadura en la Universidad de Salamanca durante su etapa clásica," Norba. Revista de Historia, 24 (2011): 225-256.
} 
nación universitaria, definiciones y aportaciones a partir de las cuales nosotros iniciamos esta pequeña reflexión y planteamos este trabajo. Las define como "asociaciones de apoyo mutuo y solidaridades de tierra y patria",, trazando una línea de evolución desde sus orígenes hasta el periodo que a nosotros nos interesa:

"Desde sus orígenes medievales los estudiantes de las universidades habían tendido a asociarse entre sí para el mutuo apoyo y defensa de intereses, al modo de los gremios urbanos. Como es natural, las agrupaciones de estudiantes tenían mucho que ver con los lazos de paisanaje y procedencias geográficas: un mismo territorio, unas mismas costumbres, una parecida idiosincrasia, añoranzas comunes y, a veces, una misma lengua o los mismos caminos a recorrer, constituían vínculos muy fuertes".

Es, por tanto, la "nación universitaria" un espacio de socialización (solidaridad y apoyo mutuo) y de afirmación colectiva (identificación "identitaria") en un marco, en esta ocasión muy concreto para el caso que estudiamos como es el de la ciudad de Salamanca durante el periodo Barroco, y para un sector de la población bien definido, en este caso también, los estudiantes matriculados en la Universidad a los que les unen lazos de paisanaje o procedencia geográfica común. Otros conceptos que aparecen asociados en la documentación al de "nación universitaria", son los de "cofradía"9 y "cuadrilla"10. Sobre ellos reflexionaremos a continuación en pos de una breve aclaración terminológica.

${ }^{7}$ Luis E. Rodríguez-San Pedro Bezares. "Cátedras, grupos de presión y naciones de estudiantes en la Salamanca del siglo XVII," en Estudios históricos salmantinos. Homenaje al P. Benigno Hernández Montes, coord. José Antonio Bonilla y José Barrientos (Salamanca: Ediciones Universidad de Salamanca, 1999), 485-510. 487. Artículo también disponible en Colegios y universidades I. Del Antiguo Régimen al liberalismo, coord. Enrique González González y Leticia Pérez Puente (México: UNAM-CESU, 2001) 107-132. Otros trabajos del mismo autor sobre el tema se irán citando a lo largo del artículo.

${ }^{8}$ Luis E. Rodríguez-San Pedro Bezares, "La nación de Vizcaya en las universidades de Castilla: (siglos XVI-XVIII)," Revista de historia moderna. Anales de la Universidad de Alicante, 20 (2002): 11-46. 22.

${ }^{9}$ La bibliografía sobre el fenómeno de las cofradías en la temprana edad moderna castellana es más amplia. De acuerdo con el Tesoro de la lengua castellana (1611) cofradía (o confraternitas) viene a ser sinónimo de hermandad. Covarrubias, Tesoro, 570 . siendo muy similar la definición que se conserva en el Diccionario de autoridades (T. II, 1729): "congregación o hermandad que forman algunos devotos para exercitarse en obras de piedad y charidad (...)”, online.

${ }^{10}$ Según Cobarruvias: "COLACIÓN (...) algunas veces significa los vezinos que son de una mesma parrochia o tribu (...)" Covarrubias, Tesoro, 335. El Diccionario de autoridades no incluye las voces "cuadrilla", "colación" o "parroquia" utilizadas en los sentidos que pudieran sernos válidas para este trabajo. 
Destaca, igualmente que la "nación universitaria", la importancia de las cofradías como asociaciones de confirmación grupal, prestigio social y principios de honor y dignidad dentro de una sociedad donde lo simbólico tiene mucha importancia. Influye también el orgullo de pertenecer a un cuerpo o corporación de carácter en cierto sentido democrático dentro de una sociedad jerárquica y desigual ${ }^{11}$. Cuestiones de afirmación externa como el estandarte, tal y como se desprende de un caso particular que después analizaremos, serán así de suma importancia, ya que se trata del símbolo de la representación del grupo al que pertenecen y en el que priman las relaciones de amistad y solidaridad, ámbito de sociabilidad dónde lo popular toma la palabra y lo aristocrático se somete, al menos en apariencia y en aquellas cofradías en las que tiene cabida la participación de elementos populares ${ }^{12}$. Como expone el artículo de Inmaculada Arias y Miguel Luis López existen cofradías devocionales, penitenciales, gremiales, asistenciales y congregaciones, cada una acogida a una advocación, ya sea mariana, de santos, a Cristo (menos frecuentes) o mixtas. Destacada es su participación en las fiestas locales ${ }^{13}$. Otras tipologías establecen diferencias entre cofradías "religioso-benéficas (destinadas a ofrecer amparo a los sectores sociales desprotegidos) y las gremiales-asistenciales (para socorros-mutuos)". ${ }^{14}$ El siglo XVII será el momento de mayor creación de cofradías. Después, en el XVIII, el gobierno tratará de controlar unas asociaciones con enorme influencia social hasta disminuir su número en el XIX; lo mismo que las naciones universitarias.

Concluiremos pues que, en tanto que en determinados casos las cofradías pueden agrupar a sus miembros en función de su origen de proceden-

\footnotetext{
${ }^{11}$ A pesar de tratarse de congregaciones aparentemente democráticas, encontramos que habitualmente son personas consideradas de mayor dignidad las que se encuentran desempeñando los cargos electos, especialmente en el caso de las naciones universitarias, pues en el de las cofradías depende del tipo de la misma, habiendo muchas cuyo carácter es íntegramente popular y, en este sentido, más igualitario.

${ }^{12}$ Inmaculada Arias de Saavedra y Miguel Luis López-Guadalupe Muñoz. "Las cofradías y su dimensión social en la España del Antiguo Régimen," Cuadernos de Historia Moderna, 25 (2005): 189-232.

${ }^{13}$ Tal y como destaca el artículo de Máximo Diago para el caso soriano: Máximo Diago Hernando, "El reforzamiento de los vínculos comunitarios a través de la fiesta en las ciudades castellanas en el marco de las cuadrillas y cofradías. Siglos XV-XVII," Revista de dialectología y tradiciones populares, T. 68, 1 (2013): 33-56.

${ }^{14}$ Ana Crespo Solana, "El patronato de la nación flamenca gaditana en los siglos XVII y XVIII: trasfondo social y económico de una institución piadosa," Studia Historica. Historia Moderna, 24 (2002): 297-329, 304.
} 
cia, podríamos asemejar los términos de "cofradía" y "nación universitaria" y no incurrir en un error, de hecho, así lo hacen las propias fuentes, las cuales nos señalan, del mismo modo, una posible línea de investigación para el fenómeno de la "nación universitaria"15. Igualmente otros conceptos de la época pueden reunir características similares, es el caso de "cuadrilla" (colaciones o parroquias), antes comentado y menos estudiado y del que se sabe menos. De acuerdo con el estudio de Máximo Diago para el caso soriano, las cuadrillas servirían para canalizar la participación del estamento pechero en la vida política local ${ }^{16}$ (del mismo modo que lo hace la nación respecto del gobierno de la corporación universitaria, como después veremos). De este modo, cada año, los vecinos pecheros de cada cuadrilla elegían un representante, el jurado, y los jurados de todas las cuadrillas designaban un procurador general del Común que anualmente se situaba al frente del gobierno del estamento pechero y lo representaba en el ayuntamiento del concejo. ¿No se parece esta forma de representación a la participación de los estudiantes de cada nación en el Claustro a través de sus representantes, los consiliarios ${ }^{17}$ ?

¿Significa esto que eran sinónimos, por tanto, cuadrilla, cofradía y nación? Nos inclinamos a pensar que no, sin embargo en la documentación a veces aparecen como conceptos equivalentes. Probablemente en la época se entendiesen las diferencias y similitudes mucho mejor que en la actualidad, y por ello en las fuentes se emplean indistintamente, si bien para la

${ }^{15}$ En el mismo artículo Ana Crespo hace constar esta dificultad de diferenciar ambos conceptos: "Desde el punto de vista conceptual es bastante complejo diferenciar los atributos de la cofradía de mercaderes de lo que era, en sentido estricto, la propia nación de comerciantes". Sin embargo destaca, en última instancia, como característica fundamental de la nación-cofradía (términos que no emplea como sinónimos en el artículo) en cuestión, la "manifestación clara de estrategia de grupo", lo que podría asemejarla también al concepto de gremio. Crespo, "Nación flamenca gaditana", 315, 303, 299.

${ }^{16}$ Máximo Diago Hernando, "La participación de los pecheros en la vida política de las ciudades castellanas: El común de los pecheros de Soria entre los siglos XIV y XVII," Celtiberia, 98 (2004): 63-118. Del mismo autor: "Las cuadrillas del Común de pecheros, una institución singular en la ciudad de Soria entre los siglos XIV y XXI," Revista de Soria, 60 (2008): 31-46.

${ }^{17}$ Véase epígrafe 2, en el que describimos cómo se conforma la representación de las naciones universitarias dentro del claustro de rector y consiliarios, así como la elección de rector. Águeda Rodríguez habla de estudiantes "catedreros" y "cuadrilleros" o caudillos de los que votaban: "que se dedicaban a buscar votos en favor de determinado opositor, a cambio de meriendas, botas de vino y otros regalos", no debiéndonos dejar indiferentes la utilización específica en este caso del término "cuadrillero", lo que nos hace indicar que las similitudes, en la época, no pasarían inadvertidas. Águeda María Rodríguez Cruz. "Vida estudiantil en la Hispanidad de ayer," Thesurus: Boletín del Instituto Caro y Cuervo, t. XXVI no 2 (1971): 355399. 374. 
historiografía actual este hecho puede presentar alguna dificultad a la hora de consultar la documentación, siendo aconsejable la diferenciación de los conceptos (dejando claro que se trata de una distinción analítica introducida por el historiador). Si bien los dos primeros han estado tradicionalmente vinculados y empleados como sinónimos por la historiografía, el tercero es menos utilizado. Hoy habría que precisar, como decimos, que se trata de conceptos diferentes. Se trata, a pesar de ello, de realidades muy similares que en muchos puntos se encuentran realizando funciones superpuestas, siendo en algunos casos difíciles de diferenciar, especialmente cuando su uso se generaliza, también por tratarse de fenómenos que no en todos los casos han sido estudiados de igual manera. Hubo cofradías universitarias o cofradías de estudiantes que no constituían naciones universitarias, las cuales poseían los fines propios característicos de una cofradía piadosa o devocional, tal y como hoy la entiende la historiografía sobre el tema. Fue el caso de la cofradía de los Naturales estudiantes, la cual, en marzo de 1621, se enfrentó a la cofradía de San Antonio de los mozos sobre el derecho a poner las armas de la ciudad en sus estandartes e insignias. Como mencionábamos con anterioridad, el elemento simbólico de exteriorización, identidad y diferenciación del grupo respecto de otros colectivos era importante en la época. De este modo, los mayordomos de la cofradía de los Naturales estudiantes, es decir, de los estudiantes salmantinos de la Universidad, con sede en la iglesia de San Antonio, se presentaban ante el tribunal del Estudio. Recordemos que la corporación universitaria tenía jurisdicción privativa, en manos del maestrescuela del cabildo catedralicio y los oficiales de la Audiencia Escolástica, tal y como explican los trabajos de María Paz Alonso ${ }^{18}$. En esta ocasión el término de cofradía no podría emplearse como sinónimo del término nación, ya que los estudiantes formarían parte de la nación de Campos, que no se menciona en el documento. Acusaban a la cofradía de San Antonio de los mozos, con sede en la iglesia de San Benito, de querer utilizar las varas y demás escudos de las armas de la ciudad para el pendón y estandarte de su

${ }^{18}$ La autora estudia el caso de la Cofradía de la cárcel del Estudio. Falta por hacer una historia sobre la Cárcel escolástica, lugar de custodia de los reos de la justicia universitaria, así como el intento de creación de una cofradía vinculada a ella (desde 1568), de carácter caritativo, para paliar las severas condiciones que, al parecer, tendría la misma, en los momentos en que el Estudio disponía de ella. Hasta el momento solamente hay referencias fragmentarias sobre dicha cofradía así como sobre la propia cárcel: M. Paz Alonso Romero, Universidad y sociedad corporativa. Historia del privilegio jurisdiccional del Estudio salmantino (Madrid, Tecnos, 1997) esp. 159 y ss. De la misma autora: "Sobre la jurisdicción y el gobierno de la Universidad de Salamanca a fines del siglo XVI," Studia Historica. Historia Moderna, XI (1993): $117-147,122$ y ss. 
cofradía, teniéndolos ellos en posesión desde tiempo inmemorial, de lo que venía, afirmaban, gran daño y prejuicio para su cofradía. Pedían que las borrasen y no las utilizasen en público ni en secreto. Ante la citación de la otra parte por el juez del Estudio, el mayordomo y varios miembros de la cofradía de San Antonio de los mozos respondieron negando la jurisdicción del maestrescuela. Éste procedió contra ellos mediante censuras y les obligó a comparecer. Consideraron que sí podían portar las armas de la ciudad porque poseían un permiso firmado por el consistorio para ello. Presentaron una licencia del concejo, justicia y regimiento de la ciudad de Salamanca firmada ese mismo mes y año, por la que se les autorizaba a portar en su pendón las armas de la ciudad, ya que de lo que se trataba, explicaron, era de hacer ver que también eran naturales de la ciudad. Los de San Antonio de los estudiantes Naturales consideraron que su cofradía era más antigua y sus miembros más principales, no pudiendo la parte contraria emular las insignias de su cofradía y que ya portaban desde antiguo en el estandarte, escudo, hachas y varas y otras partes. Presentaron un extracto certificado ante notario del consistorio ordinario en el que se acordó tal cuestión. En dicho extracto, los de San Antonio de los mozos ya preveían que el hecho de portar las armas de la ciudad entre sus insignias les acarrearía problemas:

"Nos tememos que el dicho señor maestrescuela nos molestará con censuras y por obviar este daño pedimos y suplicamos a vuestras señorías amparen nuestra causa nombrando dos cavalleros regidores salgan a ello y a pedir a los dichos maestrescuela no nos moleste y en caso de que haya de haver pleito de su parte que vuestras señorías nos amparen saliendo a la causa, la cofradía se ofrece a pagar todos los gastos que se hicieren"19.

Cuestión ante la que el consistorio llegó a un acuerdo que parecía darle la razón a la cofradía de San Antonio de los estudiantes Naturales: que la cofradía de los mozos de San Antonio, sita en San Benito, pusiese solamente las armas de la ciudad del toro y el puente, como parece se habría acordado con anterioridad ${ }^{20}$. Sin embargo, en otros casos estos conceptos sí que se emplean indistintamente y la documentación habla de cofradía refiriéndose a lo que hoy entenderíamos por nación. De manera provisional a este trabajo,

\footnotetext{
${ }^{19}$ Archivo Universitario Salmantino (AUSA). Sección maestrescuela. 3071,2. fol. 9 r y v.

${ }^{20}$ También hay ejemplos de estudios para la ciudad de Salamanca referentes al fenómeno específico de las cofradías. Francisco Javier Blazquez Vicente, "El ejercicio de la caridad en la Cofradía de la Santa Cruz de Salamanca durante la Edad Moderna," en La religiosidad popular: riqueza, discernimiento y retos. ed. Julio. A Ramos Guerreira, Miguel Anxo Pena González y Francisco Rodríguez Pascual (Salamanca: Universidad Pontificia de Salamanca, 2004), 221-226.
} 
por tanto, y a la espera de futuras investigaciones sobre el tema, entenderemos el concepto de "nación universitaria", como decíamos, menos estudiado, como una realidad más compleja que atiende a funciones más amplias que la dimensión tradicional social (asistencial) y piadosa (religiosa) que se le otorga a la cofradía.

\section{Dimensión política de las naciones universitarias: conflictividades y violencias}

Por tanto, queremos destacar por encima de todo el hecho de que las naciones representan también grupos de poder con intereses políticos y de representatividad muy específicos dentro de la Universidad y su gobierno, además de su carácter asistencial y devocional que las vincularía a las tradicionales cofradías, lo que determina su verdadera importancia en el esquema de poder universitario. El cargo anual de rector, que por lo general lo ostentaba un alumno, lo elegía el claustro de consiliarios, integrado por ocho estudiantes representantes de cada nación universitaria, a saber: Galicia, Portugal, Campos (Castilla la Vieja y León), Vizcaya (País Vasco, Navarra y La Rioja), Extremadura, La Mancha, Andalucía y Corona de Aragón, siendo la representatividad de carácter territorial y no dependiente del número de estudiantes de cada procedencia geográfica; junto con el rector. Este claustro se renovaba anualmente, siendo el rector y consiliarios salientes quienes nombran a los consiliarios y rector entrantes, según lo dispuesto en los Estatutos y constituciones de la Universidad, los cuales establecieron un marco normativo básico que regulaba la forma de proceder para todas estas cuestiones (calidad de las personas elegidas, procedencia, etc. ${ }^{21}$ ):

"La elección anual de consiliarios y rector se realizaba a partir de pactos previos entre las «naciones〉 (...) de estudiantes, en donde se daban cita las amistades, parentescos, influencias, simpatías y prestigios personales". ${ }^{22}$

${ }^{21}$ Proceso regulado por disposiciones estatutarias, las cuales, no obstante, debemos tomar como marco de referencia que no siempre se cumplió, como después veremos. Estatutos hechos por la Universidad de Salamanca. 1625. Estudio y edición al cuidado de Luis E. Rodríguez-San Pedro, (Salamanca, Ediciones Universidad de Salamanca, 1990), los títulos I, "De la elección de rector" 137. y II, "de la elección de Consiliarios" 139.

${ }^{22}$ Luis E. Rodríguez-San Pedro Bezares y Ángel Weruaga Prieto, "Vítores universitarios y naciones de estudiantes en la Salamanca del Barroco," en Matrícula y Lecciones. XI Congreso Internacional de Historia de las universidades hispánicas (Valencia, noviembre 2011). Vol. II. (Valencia: Universitat de València, 2012) 357-383, 371. De los mismos autores: "La costumbre de los vítores académicos en las universidades hispánicas," en Vida cotidiana en la España de la Ilustración. ed. Inmaculada Arias de Saavedra, (Granada: Universidad de Granada, 2012) 
De la importancia política de estos pactos dan cuenta los numerosos conflictos que generaron. Entre las funciones de este claustro, integrado por el rector y ocho consiliarios representantes de las naciones universitarias, había diversas atribuciones docentes, las más importantes referidas a cátedras: declaración de vacantes, regulación de las votaciones y su provisión, a lo que debemos sumar la elección anual de los cargos de rector y consiliarios ya mencionados. Los miembros de este claustro eran miembros de pleno derecho, asimismo, del pleno universitario. Si había consenso entre las naciones sobre estas elecciones, no había conflicto, a pesar de que no se cumpliese la norma dictada en los Estatutos y constituciones de la Universidad ${ }^{23}$. El problema surgía entonces cuando se rompía el consenso, lo que dio lugar a numerosos litigios e incluso enfrentamientos armados en los que estas solidaridades, influencias, simpatías y prestigios personales podían dar lugar a enconadas contiendas, ya fuese ante la justicia universitaria, ya fuese a través, como decimos, de luchas violentas o amenazas ${ }^{24}$. Así, en febrero de 1626, se enfrentaron ante la justicia universitaria, Álvaro de Miranda, estudiante de la diócesis y obispado de Oviedo (principado de Asturias) y Luis de Quiñones, de León, sobre el nombramiento para la consiliatura de la nación de Campos y del Reino de León. Álvaro de Miranda era estudiante de cánones de quinto año y tenía 25 años, mientras que Luis de Quiñones, clérigo, tenía 16-17 años. Ambos se disputaban la consiliatura del curso de 1625-1626. Luis de Quiñones apeló a la costumbre de que la consiliatura recayese un año en un estudiante asturiano y otro en un estudiante leonés, no pudiendo recaer dos cursos consecutivos en manos de un estudiante asturiano, así como al hecho de haber sido elegido por el rector y consiliarios salientes. No obstante, a pe-

675-695; Elogios triunfales. Origen y significado de los Vítores universitarios salmantinos (ss. XV-XVII). (Salamanca: Universidad Pontificia de Salamanca, 2011).

${ }^{23}$ A pesar de tratarse de congregaciones aparentemente democráticas, encontramos que habitualmente fueron personas consideradas de mayor dignidad las que se encontraban desempeñando los cargos electos. Los consiliarios, representantes de la nación en el Claustro de consiliarios, casi siempre fueron estudiantes a los que se aludía específicamente como personas "principales" o de "dignidad" y "calidad" apropiadas. De hecho, siempre que existió un conflicto al respecto se aludía específicamente a la necesidad de que dicho estudiante cumpliese esta característica. En otras ocasiones podía aludirse a la edad, siendo obligatorio que los consiliarios fuesen mayores de 25 años.

${ }^{24}$ En otro artículo señalábamos estas cuestiones (provisión de cátedras y elección de rector y consiliarios) como las causas más inmediatas de la violencia universitaria durante el periodo Barroco: Gustavo Hernández Sánchez, "Reyertas estudiantiles y violencia universitaria en la Salamanca del periodo Barroco: 1598-1625," Erasmo. Revista de historia bajomedieval y moderna, 1 (2014): 121-137, 128-131. y 133. 
sar de que "don" Luis de Quiñones reunía las calidades necesarias, así nobleza como las demás, no tenía los años necesarios para desempeñar el oficio de consiliario. El fallo del maestrescuela supone otro ejemplo más de que la norma es un marco de referencia que debemos tratar con precaución, el cual no siempre se tuvo en cuenta, puesto que confirmó la elección en Luis de Quiñones y recomendó que en lo sucesivo se tuviese más cuidado en la elección de consiliarios y se le notificase previamente ${ }^{25}$. Probablemente tuviese mucho que ver en la decisión del maestrescuela los acuerdos previos tomados dentro de la nación y el propio claustro de consiliarios. Entrometerse en dichas decisiones, como después veremos, podría suponer una amenaza para la paz dentro del Estudio, pues otros casos no se resolverán de forma tan sencilla.

\section{La paz rota}

Es a este punto al que nos interesa traer esta consideración sobre el concepto de "nación universitaria", pues fueron ciertamente las luchas banderizas que a menudo se produjeron entre naciones (incluso dentro de las mismas) por la elección de consiliarios y rector, así como en las votaciones a cátedras, las que han llevado a la historiografía a considerar una atmósfera universitaria especialmente violenta. No obstante, nos recuerda Margarita Torremocha que estos desórdenes públicos, "en ningún momento nos pueden llevar a confundir la situación con un enfrentamiento continuado entre comunidades"26; así, en aquellos momentos en que la alteración del orden público fue significativa la Corona intervino de forma contundente, entrometiéndose incluso en la jurisdicción universitaria que protegía al estamento estudiantil o suspendiendo algunos de sus privilegios y prerrogativas, como así sucedió entre 1630 y 1640, cuando "la existencia de pactos y concordias para acrecentar los sufragios, llevaron" según indica Luis E. Rodríguez-San Pedro "a una verdadera desintegración académica que (...) asumió verdaderas formas de guerra de bandos"27 en las que también se vieron envueltas los colegios. Por ello, las provisiones de cátedras por votos de estudiantes fueron suprimidas provisionalmente en 1623 y definitivamente en 1641, quedando la provisión a partir de dicha fecha en manos del Consejo de Castilla. Ejemplo de ello es lo sucedido al inicio

\footnotetext{
${ }^{25}$ AUSA 3070,21. Otros casos apuntan también en esta dirección.

${ }^{26}$ Margarita Torremocha Hernández, "Ciudades universitarias y orden público en la Edad Moderna," Cuadernos de Historia Moderna. Anejos. III. (2004): 137-162. 140.

${ }^{27}$ Rodríguez-San Pedro, “Cátedras, grupos de presión y naciones”, 36.
} 
del curso de 1635-1636, en el día de San Martín (11 de noviembre ${ }^{28}$ ), cuando se produjeron dos muertes de estudiantes vizcaínos a manos de estudiantes andaluces, lo que dio inicio a un largo pleito entre la Universidad y su tribunal con el juez comisionado por el Consejo para investigar los casos.

A finales de 1635, en un enfrentamiento entre estudiantes andaluces y vizcaínos con motivo de una elección a cátedra, morían Domingo de Azpilaga y Martín de Araz. Consideramos que este suceso fue suficientemente grave para considerarlo el origen de la suspensión temporal por parte del Consejo Real de las votaciones durante el curso de $1635-1636^{29}$. El pleito no deja ninguna descripción de lo ocurrido, salvo los nombres de las víctimas, pues se centra en el enfrentamiento que se produjo entre el alcalde de casa y corte, don Juan de Morales, a quien envió el Consejo para esclarecer lo sucedido, y la justicia universitaria, quien consideró dañados sus privilegios ya que una de las primeras acciones de este hombre fue arrestar en su domicilio al juez del Estudio, licenciado Vicente de Bañuelos, al considerar que no habría procedido con la rectitud necesaria en la averiguación y castigo de los crímenes. En el pleito intervinieron el fiscal de la Audiencia Escolástica, en defensa de su oficial cuestionado, y la propia Universidad como parte, a través del síndico, licenciado Cornejo Velasco, persona encargada de velar por la salvaguarda de los privilegios, Estatutos y constituciones del Estudio ${ }^{30}$.

En efecto, como indica Luis E. Rodríguez-San Pedro, en el periodo de 1636-1639 las votaciones a cátedra se cuestionaron desde diversos sectores del claustro universitario, especialmente doctores y maestros, pidiendo su

${ }^{28}$ Día en que se elige el oficio de rector.

${ }^{29}$ En 1635 una comisión delegada del claustro reformaba la provisión de cátedras a instancia del Real Consejo de Castilla, tal y como indica Luis E. Rodríguez-San Pedro: "En claustro pleno de 20 de noviembre de 1635 se informa de cómo el Consejo había decidido suspender temporalmente (por cuatro meses) la provisión de cátedras, y enviar un alcalde de Casa y Corte a la pesquisa [de las muertes de los estudiantes vizcaínos citados]. Como consecuencia de todo ello, el 23 de abril de 1636, el maestrescuela informaba de la decisión definitiva tomada por el Consejo, suprimiendo los votos de estudiantes en las universidades de Castilla" Rodríguez-San Pedro, “Cátedras, grupos de presión y naciones”, p. 498.

${ }^{30}$ AUSA 3122,7. El enfrentamiento se resolvía, finalmente, mediante una carta de provisión real fechada en 14 de enero de 1636 por la que se pedía al maestrescuela absolviese a su juez de casa y corte, quien actuaba bajo su comisionado, y dejase la causa en manos del Consejo Real. Sobre las cuestiones implícitas en este pleito referentes a los límites de la jurisdicción del fuero académico y el poder real del maestrescuela, dignidad que se encontraba al frente del tribunal de la Audiencia Escolástica y que acogió los casos, pleitos civiles y criminales, que dieron forma al fuero y privilegio universitario, reflexionamos en la investigación de tesis doctoral que desarrollamos bajo el título "Poder y fuero académico de las universidades hispánicas. La Salamanca del Barroco," dirigida por el profesor Luis E. Rodríguez-San Pedro. 
prohibición porque el problema comenzaba a hacerse endémico. A pesar de todo, fue el propio Consejo el que las mantuvo hasta 1639-1641, siendo la muerte de don Pedro de Villanueva, estudiante andaluz, a manos de estudiantes portugueses en un enfrentamiento en el que hay un gran número de heridos, en 1640, y la de un estudiante de Campos, en un enfrentamiento entre los de Vizcaya y Campos con los de Extremadura y Andalucía, las que provocan definitivamente la prohibición de las votaciones a cátedras mediante carta de provisión real emitida en Madrid el 11 de diciembre de $1641^{31}$. La situación habría llegado a ser verdaderamente insostenible, los odios entre naciones muchos, y las posibilidades de mediación por parte del maestrescuela y los jueces del Estudio y otros oficiales universitarios, pocas. El complejo juego que mantenía la paz a pesar de las serias amenazas de violencia, definitivamente, se había roto. El Consejo decidía pues, cortar por lo sano, al menos en lo que a votaciones a cátedras se refiere, pues la conflictividad seguiría haciéndose patente en las elecciones de rector. Con estos movimientos se irá también desmantelando progresivamente la importancia del papel que los estudiantes jugaron dentro del sistema de poder universitario, que en Salamanca hasta el momento mantenía un aparente "equilibrio de poderes" entre doctores y maestros y estudiantes, configurándose como un modelo de carácter medievalizante en el que la participación estudiantil proporcionaba un aparente manto democrático al gobierno universitario, a diferencia de las otras dos universidades mayores, Valladolid y Alcalá, las cuales presentaban un modelo distinto, más moderno $y$, por consiguiente, de talante más autoritario ${ }^{32}$.

\section{La paz amenazada}

Consideramos, no obstante, con Margarita Torremocha, que en el resto de las ocasiones la amenaza de conflictividades violentas por parte del estamento estudiantil se produjo para tratar de defender sus privilegios y tradiciones o costumbres académicas y que "en ningún [o en pocos] caso[s] pueden ser consideradas alteraciones graves del orden público"33; tal y como sucedía en

\footnotetext{
${ }^{31}$ Rodríguez Rodríguez-San Pedro, "Cátedras, grupos de presión y naciones", 502.

${ }^{32}$ Mariano Peset, Obra dispersa. La Universidad de México (México D.F. UNAM-IISUE, 2012), 20.

${ }^{33}$ Torremocha, "Ciudades universitarias y orden público," 161. "Los tumultos y las algaradas estudiantiles fueron moneda corriente en la Universidad del Antiguo Régimen, pero, los motores que pusieron en marcha las protestas estudiantiles estuvieron relacionadas sistemá-
} 
noviembre de 1628, cuando los estudiantes de la nación portuguesa amenazaron con provocar disturbios si se aceptaba la elección de un consiliario por parte del rector que no era de su agrado, amenazando incluso con matarle si se mantenía su elección, lo que obligó al maestrescuela a intervenir, con no pocas dificultades, para conservar la paz. Después de todo, presumimos que todos los miembros de la comunidad universitaria estarían prestos a mantener dicha paz, del mismo modo que a romperla cuando fuese preciso en defensa de unos intereses políticos bien definidos dentro del gobierno universitario. En este sentido, debemos poner de manifiesto que el recurso a la violencia en la temprana Edad Moderna castellana no fue tan restringido como lo es en la actualidad, monopolizado casi exclusivamente por los mecanismos de dominio estatales ${ }^{34}$. Cabía, por tanto, la posibilidad de la defensa de los derechos y privilegios de cada comunidad incluso mediante la violencia, cuestión que la comunidad universitaria supo emplear también mediante la amenaza de la misma en aquellos momentos en que lo consideraron oportuno, estableciendo lo que podemos considerar como un diálogo sobre el poder. Como veremos en otros casos, la amenaza de provocar disturbios estuvo siempre presente en las alegaciones ante la justicia universitaria, y más concretamente ante el maestrescuela, interesado en este sentido en mantener la paz dentro de la comunidad como instancia mediadora externa. En el caso que estudiaremos a continuación, en cambio, éstas amenazas fueron mucho más apremiantes, lo que nos presenta al maestrescuela del Estudio como una pieza relevante en este complejo ajedrez, no exenta de limitaciones, lo que llevó finamente a intervenir al Consejo de Castilla cuando las cosas parecieron ponerse feas.

Fue la elección del nuevo rector, don Francisco Acosta de Luna, lo que generó el descontento entre varias naciones ${ }^{35}$. Sin embargo, la más disgustada parecía ser la nación portuguesa, que solicitaba al maestrescuela, don Francisco Arias Maldonado, que anulase la elección del consiliario Francisco de Acosta. Ante él se presentaron en noviembre de 1628 los mayordomos de la nación de Portugal. Afirmaban que el elegido no reunía todas las calidades

ticamente a lo largo de la Modernidad con la defensa de sus privilegios frente a intromisiones externas, y con sus deseos de mantener la tradición en sus diversiones o costumbres académicas" Torremocha, "Ciudades universitarias y orden público," 141.

${ }^{34} \mathrm{Al}$ respecto, son interesantísimas las notas de Piere Bordieu. Sobre el Estado. Cursos en el Collège de France (1989-1992), (Barcelona: Anagrama, 2014).

${ }^{35}$ La nación gallega también recurrió la elección de su consiliario, don Francisco de Castro. El maestrescuela suspendió temporalmente su nombramiento. El rector, por su parte, recomendó a éste que no se entrometiese, temiendo que si quedase vaca alguna consiliatura se procedería con violencia. No obstante, enseguida veremos que el rector era parte interesada en la elección de estos consiliarios. AUSA 3094,12. 
para ejercer el cargo de consiliario y que por esa razón muchos estudiantes portugueses se habían inquietado viniendo a escuelas con ánimo de impedirlo por la fuerza, estando las cosas en peligro de que sucediesen algunas desgracias. Tan mala parecía la situación que don Alonso Henríquez, juez Escolástico, ordenó la prisión de más de cien hombres, todos ellos portugueses, unos en la cárcel pública y otros en sus casas. Suplicaban estos hombres que, por bien de la paz y para excusar inquietudes y alborotos, se ordenase la nulidad de la elección de Francisco de Acosta como consiliario de la nación portuguesa. Informaba al maestrescuela un colegial del Colegio mayor de Cuenca de que los portugueses no habían de aceptar el nombramiento de este consiliario bajo ningún concepto, y aún es más, tratarían de impedirlo por la fuerza porque el designado no era conocido (es decir, no gozaba del prestigio necesario para representar a su nación). Afirmaba que todos los estudiantes presos eran portugueses y que ello acrecentaba aún más su enojo. Aconsejó, por servicio de Dios y quietud de la Universidad, que ese año no fuese nombrado el dicho Francisco de Acosta consiliario, pues los portugueses se revelarían. Otro testigo afirmó que, de confirmarse la elección de Francisco de Acosta, por la noche le habrán de buscar para matarle. Los ánimos se encontraban verdaderamente caldeados. La amenaza de ruptura de la paz era inminente. Por ello el maestrescuela emitió un auto por el que: "para remedio de los alborotos e inquietudes que se pueden seguir de ser consiliario el dicho don Francisco de Acosta debía de mandar y mandó por ahora no sea admitido a la dicha consiliatura (...)"36 ni se le tome por consiliario bajo pena de excomunión mayor y multa de mil ducados.

El rector entrante, don Francisco Sarmiento de Luna, recibida la notificación del auto, consideró que la elección de Francisco de Acosta como consiliario de la nación portuguesa era buena y justamente hecha conforme a los Estatutos y constituciones del Estudio. Añadía que la oposición que afirmaba que era persona falta de alguna calidad era falsa y maliciosa. Pidió al maestrescuela que no se dejase llevar por quienes eran apasionados y le recordó que solamente podría intervenir en la elección en caso de discordia por empate de los votos, lo que no habría sucedido. Por su parte, el maestrescuela consideró que no se había procedido conforme a Estatutos y constituciones en la elección, habiendo muchos alborotos y ruidos por la ciudad, lo que le permitiría abrir cabeza de proceso para que con ella se proveyese lo que fuere convenido en base a su competencia, no como juez cancelario privativo del Estudio sino como conservador y ejecutor de los Estatutos y

\footnotetext{
${ }^{36}$ AUSA 3094,12, fol. 5 r.
} 
constituciones de la Universidad. De nuevo, detrás de todos estos conflictos, vislumbramos como trasfondo la elección del cargo de rector ${ }^{37}$. El maestrescuela emitió un auto por el que consideraba que:

"debía de mandar y mandó por obviar los grandes inconbenientes y motines que se esperan [que el señor rector] junte claustro de consiliarios y haga electión de rector con aperçebimiento que no lo haçiendo Su Merçed proçederá conforme a las constituçiones a haçer justiçia además que todos los daños que se siguieren por causa de su detençión correrán por su cuenta (...)"38.

El rector, por su parte, contestó que, conforme a Estatutos y constituciones, disponía de tres días para hacer la elección. No consideraba acertado aventurar su autoridad ya que se temía que pudiese haber tumultos en dicho claustro, por lo que se mostraba reticente a aparecer en público. Por ello pedía personas que le acompañasen y le defendiesen, acusando al maestrescuela de llevarlo "por fuerça y violentamente entrometiéndose en su jurisdiçión"39. Concretamente, requirió la presencia de cien hombres armados, lo que puede darnos una imagen aproximada de la gravedad del asunto, y afirmó que era el maestrescuela el que procedía contra él. Instaba a que, si fuere precisa otra elección, se reuniese con él en su casa (la del maestrescuela) y con los representantes de las naciones para evitar cualquier tipo de violencia. Aparentemente, la presencia de estas personas calmaría los ánimos e impediría las posibles agresiones que pudiesen cometerse contra el rector así como cualquier otro tipo de enfrentamiento banderizo. Como vemos, las cosas se estaban llevando al límite. Finalmente, el conflicto se resolvía por un auto emitido desde Madrid, el cual dejaba las cosas en el estado en el que estaban hasta que el Consejo determinase, es decir, con la elección del rector en suspensión por la anulación por parte del maestrescuela de la elección de los consiliarios de Portugal y Galicia, a pesar de que de facto todos, rector y consiliarios, estuviesen en posesión de los cargos. Previamente, el maestrescuela había convocado

${ }^{37}$ Tal y como ponía de manifiesto el testimonio de un estudiante navarro, natural de Pamplona, en la información recogida por el juez del Estudio a instancia del maestrescuela, quien afirmaba que de unos años a esta parte la Universidad, sus colegios y comunidades, andaba alborotada sobre la elección de rector y que era causa de muchas grandes desgracias sino se remediaba "por estar todo dividido en bandos" AUSA. 3094,12, fol. 6 v. y que no bastaba la autoridad del maestrescuela. Recomendaba su intervención en las elecciones para que se hiciesen conforme a los Estatutos y constituciones del Estudio. Del mismo tenor declararon otros testigos, uno de los cuales consideró que se había llegado a tal situación "por competirla personas poderosas" AUSA. 3094,12, fol. $7 \mathrm{v}$.

${ }^{38}$ AUSA. 3094,12, fol. 9 r.

${ }^{39}$ AUSA. 3094,12, fol. 9 r. 
al rector saliente, don Claudio Pimentel, y al resto de doctores y maestros para tratar el tema. Probablemente se habrían reunido para valorar los pros y los contras en aras de evitar los enfrentamientos armados. Acataron esta solución de compromiso y el maestrescuela ordenó el cumplimiento del auto bajo pena de excomunión mayor para quien provocase algún disturbio. Pidió al rector saliente que acudiese al claustro para el que se le había convocado y en el que se leyó dicho auto. Éste al parecer no acudió por miedo a la violencia que pudiese producirse. La paz, después de todo, seguía amenazada.

\section{La paz}

Sin embargo, lo más habitual fue que estas cuestiones se resolviesen de manera más sencilla, es decir, sin necesidad de amenazas o de violencia. Así, entre noviembre-enero de 1615-1616, los estudiantes de las provincias de Vizcaya, La Montaña y La Rioja, acudieron ante el maestrescuela para evitar que el consiliario saliente nombrase un consiliario navarro, el otro territorio que integraba a la nación vizcaína, saltándose el turno de alternancia en la representatividad de la nación y que al parecer mantenía la nación como norma consuetudinaria ${ }^{40}$. Así, se presentaron ante el cancelario Alonso Guillén de la Carrera varios estudiantes naturales de los territorios de Vizcaya, la Montaña (arzobispado de Burgos) y la Rioja, en nombre de sí y de todos los demás estudiantes naturales de las otras tres provincias que conformaban la nación de Vizcaya, para que don Francisco de Occon y Ciriza, natural del reino de Navarra y consiliario de la Universidad, nombrase por sucesor en el oficio de consiliario a un estudiante en quien concurran las calidades necesarias y que fuese natural de una de las tres provincias referidas y no del reino de Navarra, conforme a la costumbre que tenían de que el cargo fuese rotativo, cuestión que llevarían incumpliendo los navarros desde hacía al menos tres cursos. Solicitaron que se restituyese a su parte la posesión que tenían de suceder en el oficio de consiliario según el orden descrito y, asimismo, se mandase que no se nombrase consiliario del reino de Navarra sino de las provincias de Vizcaya, la Montaña o la Rioja y que no admitiesen el rector y consiliarios elección hecha en otra manera, declarando la elección nula. Advertían que de la elección podían resultarse "diferencias muy grandes y pleito muy prólixo entre los estudiantes de las dichas provincias y

${ }^{40}$ Detrás de esta elección, de nuevo, muy probablemente se encontraban las alianzas del rector saliente y algunos consiliarios para controlar la elección del rector entrante. 
reyno de Navarra en menoscabo de la authoridad desta Universidad y perjuicio grande de los estudiantes" y reclamaban "poder acudir con tiempo a los daños que se pueden seguir" ${ }^{\prime 1}$. De nuevo, vemos una amenaza velada a la paz y quietud del Estudio. Don Francisco de Occon y Ciriza, en cambio, solicitaba que se diese por nulo el auto del juez y que se permitiese elegir consiliario sin que tuviese que ser de Vizcaya, la Rioja o la Montaña, afirmando que la información que incluía la parte contraria no concluía cosa cierta y que no existía ningún estatuto que lo impidiese. Consideraba que los testigos que declararon eran parte interesada, y continuaba afirmando que la costumbre no obligaba, tal y como no habría obligado en años anteriores. Señalaba asimismo que, conforme a los Estatutos y constituciones de la Universidad, su parte debía nombrar a un consiliario que fuese de los obispados de Pamplona, Calahorra, Osma, Palencia, Segovia y arzobispado de Burgos, sin que se le obligase ninguna otra cosa. Pero los representantes de las provincias tuvieron que acudir de nuevo al cancelario al considerar que se había cometido un desacato grave al haberse elegido consiliario a Gabriel de Estaba, natural de la ciudad de Pamplona, reino de Navarra. Advertían que si no procedía contra dicha elección podía dar lugar a que "tres provincias tan numerosas de estudiantes en esta Universidad se inquieten y entre ellas y la de Navarra [h]aya pendençias y ruydos" ${ }^{22}$. El juez accedía y mandó que no se admitiese la elección bajo pena de diez mil maravedís.

\section{Conclusiones}

En definitiva, más allá de las consideraciones sobre el término de nación universitaria y su necesaria diferenciación con los de cofradía o cuadrilla, nos interesa resaltar que, a la tradicional definición de la nación universitaria

${ }^{41}$ AUSA 3045, 7, fol. 2 v. Ese mismo día presentaban ante el juez "probanza” (declaración) por la que testificaron varios colegiales de San Bartolomé, colegio en el que la presencia de estudiantes de la nación vizcaína era prolija, y en la que afirmaron que la cofradía de Vizcaya no poseía estatutos validados por autoridad apostólica, sino conformados por costumbre. El turno de consiliarios que habrían establecido sería el de vizcaínos, navarros y riojanos, y el de la rioja habría de nombrar a un montañés, y que la concordia se habría guardado desde hace al menos veinte años a esta parte, salvo los últimos cursos. Recordemos que, en la época, la costumbre también constituía derecho, denominado derecho consuetudinario, el cual no necesita aparecer por escrito ni estar sancionado por otra autoridad mas allá de la tradición (costumbre) que representaba. Finalmente, un auto del juez ordenaba que se guardase la costumbre de la nación de Vizcaya y que se eligiese consiliario conforme a ella.

${ }^{42}$ AUSA 3045, 7, fol. 23 r. 
como espacio de socialización y afirmación colectiva de los estudiantes procedentes de las mismas zonas geográficas a los que les unían vínculos sociales y culturales comunes, incluyendo elementos identitarios y de solidaridad (paisanaje), debemos añadir un destacado componente político de representatividad en los órganos de gobierno universitario, tanto en el claustro de rector y consiliarios como en el claustro pleno, cuyas funciones hemos tenido ocasión de ver, así como en otros momentos en los que su participación cobraba importancia, como pudieron ser las votaciones a cátedra. Cuestión que le da a la nación universitaria una dimensión más amplia y compleja que debería comenzar a ser tratada de manera más explícita.

En efecto, las naciones universitarias funcionaban de facto como importantes grupos de poder dentro del Estudio. Este elemento de carácter político ha de ayudarnos a comprender el cierto clima de violencia de que en algunas ocasiones se impregnó la atmosfera universitaria, especialmente significativo en las décadas de 1630 y 1640, como hemos podido comprobar, lo que llevó al Consejo a prohibir de manera definitiva las votaciones a cátedras con el fin de evitar los enfrentamientos violentos entre naciones, los cuales ya habían motivado varias muertes en los últimos años. El resto del tiempo, la amenaza de enfrentamientos violentos funcionaría como una manera de hacer respetar tanto las costumbres de representatividad dentro de las distintas comunidades que integraban la corporación universitaria, como los propios Estatutos y constituciones de la Universidad, elementos que, a pesar de ello, se supeditaban de manera implícita a los acuerdos tomados tanto dentro de las propias naciones como entre ellas, lo que nos obliga a mirar de otro modo el carácter institucional y la efectividad real de la normativa universitaria. En unos casos vemos como ésta pareció respetarse, pero en otros ni el propio maestrescuela fue capaz de hacer valer su autoridad para mantener la paz, siendo el Consejo Real el que tuvo que encargarse de ello. Podríamos decir que, al margen del marco normativo universitario y las instituciones y cargos designados para mantenerlo, de facto se practicaba una política de hechos consumados, en una sociedad en la que el monopolio de la fuerza no era exclusivamente estatal.

Los casos expuestos nos dan las claves de un fenómeno cuya complejidad exige un análisis más extenso que el mero hecho de considerar un estamento estudiantil desordenado (o especialmente violento) y amparado por el fuero académico o fuero universitario en sus afrentas a la comunidad, tanto local, en referencia a sus fricciones o enfrentamientos con la ciudad, como dentro de la propia comunidad universitaria, en referencia a los propios enfrentamientos entre estudiantes, casi siempre agrupados bajo la 
bandera de alguna nación universitaria y en defensa de sus intereses de gru$\mathrm{po}^{43}$. Como hemos tenido ocasión de ver, estos enfrentamientos no fueron cotidianos, sino que se manifestaron en ocasiones puntuales, algunas de las cuales provocaron la reacción resoluta por parte de la Corona para remediar estos desórdenes. Mientras, el resto del tiempo la amenaza de ruptura de la paz se configuraba como un juego dialéctico, una especie de tira y afloja (negociación política) que nadie deseaba romper pero cuyas consecuencias, en algunos casos, fueron inevitables.

En último lugar, debemos considerar, en este sentido, a la comunidad universitaria salmantina de la temprana Edad Moderna también como una corporación fragmentaria, en la que multitud de intereses enfrentados se reunían para dar cuerpo a la corporación universitaria en mayúsculas. Es decir, que la conflictividad de puertas adentro del Estudio por el control de los órganos de gobierno fue en algunos casos más significativa que la que pudiese presentar la corporación en su conjunto de cara al exterior; otras veces, estos dos elementos se entrelazaron. Si bien, toda esta conflictividad se trató de resolver también de puertas adentro. Salvo por los casos de violencia y éstos registros judiciales que nosotros hoy estudiamos, debemos suponer que la mayor parte de las veces estas cuestiones se resolverían en negociaciones privadas, tanto dentro de los propios grupos de poder como entre ellos e instancias mediadoras como el propio maestrescuela o el mismo Consejo Real, en caso de producirse su intervención.

\section{Bibliografía}

Álvarez-Ossorio Alvariño, Antonio y Bernardo J. García García (eds.). La Monarquía de las naciones. Patria, nación y naturaleza en la Monarquía de España. Madrid: Fundación Carlos de Amberes, 2004.

Bordieu, Pierre. Sobre el Estado. Cursos en el Collège de France (1989-1992). Barcelona: Anagrama, 2014.

Covarrubias Horozco, Sebastián DE. Tesoro de la lengua castellana o española. Ed. integral e ilustrada de Ignacio Arellano y Rafael Zafra. Madrid: Iberoamericana, 2006.

${ }^{43}$ Existen limitaciones para su estudio, una de ellas y muy destacada es el hecho que parece que dichas naciones no poseían Estatutos ni constituciones escritos, a juzgar por lo declarado en la documentación para la nación vizcaína, lo que sin duda nos daría jugosa información sobre su funcionamiento interno. 
Diccionario de autoridades, 1726-1739. (citado el 15 de junio de 2015), editado por la Real Academia Española de la Lengua (RAE), disponible en http://www.rae.es/recursos/diccionarios/diccionarios-anteriores1726-1996/diccionario-de-autoridades

Estatutos hechos por la Universidad de Salamanca. 1625. Estudio y edición al cuidado de Luis E. Rodríguez-San Pedro. Salamanca: Ediciones Universidad de Salamanca, 1990.

HERNÁNDEZ SÁnCHEZ, GuSTAVO. "Reyertas estudiantiles y violencia universitaria en la Salamanca del periodo Barroco: 1598-1625." Erasmo. Revista de historia bajomedieval y moderna, 1, (2014): 121-137.

HoBSBAWM, ERIC. Naciones y nacionalismo desde 1780. Barcelona: Crítica, 1991. Kibre, PeARL. The Nations in the Medieval Universities. Cambridge: Mediaeval Academy of America, 1948.

Marcos De Dios, ÁNGEl. Portugueses na Universidade de Salamanca (15501580). Salamanca: Luso-Española de Ediciones, 2005.

MARCos DE Dios, ÁNGEL. "Estudiantes de Brasil en la Universidad de Salamanca durante los siglos XVI y XVII." Revista de Historia, 5 (1976): 215-230.

Peset, Mariano. Obra dispersa. La Universidad de México. México (D.F.): UNAM-IISUE, 2012.

Recio Morales, Óscar. "Los espacios físicos de representatividad de las comunidades extranjeras en España. Un estado de la cuestión”. En Las corporaciones de nación en la Monarquía Hispánica (1580-1750). Identidad, patronazgo y redes de sociabilidad, editado por Bernardo J. García García y Óscar Recio Morales. Madrid, Fundación Carlos de Amberes: 2014.

Recio Morales, Óscar. "Redes de nación y espacios de poder en la Monarquía Hispánica: un estado de la cuestión" en Redes de nación y espacios de poder. La comunidad irlandesa en España y la América española, 1600-1825, editado por Óscar Recio Morales. Valencia: Ministerio de Defensa, 2012.

Ridder-Symoes, Hilde DE. (ed.). Historia de la Universidad en Europa, vol. II. Las Universidades en la Europa Moderna Temprana (1500-1800). Bilbao: Universidad del País Vasco, 1999.

Rodríguez-San Pedro Bezares, Luis Enrique y Ángel Weruaga Prieto. "Vítores universitarios y naciones de estudiantes en la Salamanca del Barroco". En Matrícula y Lecciones. XI Congreso Internacional de Historia de las universidades hispánicas (Valencia, noviembre 2011). Vol. II. Valencia: Universitat de València: 2012.

Rodríguez-San Pedro Bezares, Luis Enrique y Ángel Weruaga Prieto. "La costumbre de los vítores académicos en las universidades hispá- 
nicas". En Vida cotidiana en la España de la Ilustración, editado por Inmaculada Arias de Saavedra. Granada: Universidad de Granada, 2012.

Rodríguez-San Pedro Bezares, Luis Enrique y Ángel Weruaga Prieto. Elogios triunfales. Origen y significado de los Vítores universitarios salmantinos (ss. XV-XVII). Salamanca: Universidad Pontificia de Salamanca, 2011. Rodríguez-SAn PEdro BezAREs, Luis EnRIQUe. "La nación de Vizcaya en las universidades de Castilla: (siglos XVI-XVIII)." Revista de historia moderna. Anales de la Universidad de Alicante, 20 (2002): 11-46.

Rodríguez-SAn PEdro BEZARes, LuIS EnRIQUe. "Cátedras, grupos de presión y naciones de estudiantes en la Salamanca del siglo XVII". En Colegios y universidades I. Del Antiguo Régimen al liberalismo, editado por Enrique González González y Leticia Pérez Puente. México (D.F): UNAMCESU, 2001.

Rodríguez-SAn PEdro Bezares, Luis EnRIQue. “Cátedras, grupos de presión y naciones de estudiantes en la Salamanca del siglo XVII". En Estudios históricos salmantinos. Homenaje al P. Benigno Hernández Montes, editado por José Antonio Bonilla y José Barrientos. Salamanca: Ediciones Universidad de Salamanca, 1999.

Rubio Muñoz, Francisco Javier. "La nación de Extremadura en la Universidad de Salamanca durante su etapa clásica." Norba. Revista de Historia, 24 (2011): 225-256.

Ruiz RodríGuEZ, José IGNACIO, "Protonacionalismo e identidades en Europa." En Construyendo identidades: del protonacionalismo a la nación, editado por José Ignacio Ruíz Rodríguez e Igor Sosa Mayor. Alcalá: Universidad de Alcalá, 2013.

Ruiz Rodríguez, José Ignacio e Igor Sosa MAYor. Identidades confesionales y construcciones nacionales en Europa (ss. XVI-XIX). Alcalá: Universidad de Alcalá, 2012.

TAMBURRI, PASCUAL. "La nación de las Indias en la Universidad de Bolonia (siglos XIV-XIX). Raíces medievales de la cultura hispano-americana." Espacio, Tiempo y Forma, serie IV, Historia Moderna, t. 13 (2000): 339-364.

TORREMOCHA HERnándEZ, MARGARITA. "Ciudades universitarias y orden público en la Edad Moderna." Cuadernos de Historia Moderna. Anejos. III. (2004): 137-162. 